\title{
Tire-Road Friction Coefficient Estimation and Experimental Setup Design of Electric Vehicle
}

\author{
C.Elmas, U.Güvenç, and M.U.Doğan
}

\begin{abstract}
Nowadays, electric vehicles have become an important area because of air pollution, increasing use of renewable energy sources and being exhausted of oil fuels. In our country even the usage of electrical vehicles is not widespread nowadays, but also very popular and it is thought that it will increase. In this area, new studies and projects appear continuously Real systems are moving systems and it is difficult and expensive to evaluate by electrical vehicles; therefore an experiment mechanism has been created. In this study two fixed magnet synchronous hub motors have been used as wheels and the other one as load. In order to find the speed of the wheel, load value and coefficient of friction related to sliding, Burckhardt model has been used and the results obtained with different speed and road conditions have been presented here.
\end{abstract}

Index Terms - HUB Motor, Electric vehicles, Burckhardt model, Slip Ratio, Friction Coefficient

\section{INTRODUCTION}

$\mathrm{N}$ OWADAYS, productivity and saving of energy subjects have become very important because of pollution, decreasing amount of petroleum and energy problems. Natural gas, water and oil are very important energy resources. If we consider our lands geographically, water is our most important energy resources. However, it is a fact that the earth is balance has been damaged because of global warming and if precautions have not been take earth will face to face with drought [1]. The most important problem is that oil is not an external energy resource and it will be exhausted in a short time [2]. The idea of moving reliable, effective and environmentfriendly electrical energy vehicles with electrical motors can be thought as the starting point of electrical vehicles [3].

In the history, Improving first electrical vehicles have started in 1835 and electrical railway has been produced in 1835 and electrical railway has been produced in 1835. Lead acid batteries have been improved in 1859 and then their usage at the electrical vehicles have been become an important transition point [4].

C. Elmas, Electrical-Electronic Engineering Department, Technology Faculty, Gazi University, P.O. Box 06200, Ankara, Turkey, (e-mail: cetinelmas@hotmail.com ).

U. Güvenç, Electrical-Electronic Engineering Department Chair, Technology Faculty, Düzce University, P.O. Box 81000, Düzce, Turkey, (e-mail: ugurguvenc@duzce.edu.tr).

M.U. Doğan, Electronic and Automation Department, Bolu Vocational High School, Abant İzzet Baysal. University P.O. Box 14200, Bolu, Turkey, (email:muhdogan@yahoo.com)
Worries about pollution and oil prices have caused the automotive industry is improving electrical vehicles rapidly.

The structure of electrical vehicle is composed of inverter circuit which has been made up for power switching components, batteries group as energy storage part, control systems and mechanic power transmission system. Electrical vehicles have made advantages than classical cars, with internal-combustion engines because of not producing waste gases and not using motor oils, being environment friendly, not needing gearbox, winning back the energy at the time of braking and running silently. However, electrical vehicle cannot take place of a gasoline car because of having heavy, bulky car batteries, limited capacities, long time of filling and having bad proportions of power-weight and power/volume of electrical motors. Also control of electrical vehicles is a very important point of security. A complete modelling should be made for a wide control. Possible conditions should be taken into consideration. In this study, an experiment mechanism consisting by two hub motors has been designed in order to model electrical vehicles. One of the hub motors used at the mechanism has been chosen a wheel of the vehicle and the other one as the load. Because the road load, which has been applied according to the road conditions, has changed, in order to find wheel speed and load value, Burckhardt Model [5] has been used for using the motors at the experimental mechanism, results reference values of the different speed and road condition have been shown.

\section{HUB MOTORS}

Hub motors are electrical motors assembled at the central of wheel of the vehicle and they can revolve the wheel directly. These motors have took place at the electrical bicycles, ATV's and electrical vehicles mostly. Four wheels driving by an electrical motor is a widely used method at the hybrid vehicles. However, four wheels driving by an electrical motor has caused some advantages and disadvantages. The most important advantage is increasing of energy productivity. There should be a lot of power train in order to transfer kinetic energy to the wheels by a central motor, on the other hand, wheel motors provides to avoid losses created by this power train. Because it is not necessary to have differential gear, drive shafts, provides decreasing of vehicle weight. Also having control of each motors independently provides the usage of algorithms easily as traction control system. On the other hand, because of motors fitted in the wheel causes increasing of weight of wheel, convenience of driving can be decreased. In such motors, wheel shaft is directly linked to the motor. 
Because of there is not a physical mediator at the time of power transfer, productivity is high at this motors. The stable windings in the motor create a specific electromagnetic field. Wheel shaft starts to turn with the effect of this electromagnetic field [6]. Electric motors have their greatest torque at startup, making them ideal for vehicles as they need the most torque at startup too.

Hub motor electromagnetic fields are supplied to the stationary windings of the motor. The outer part of the motor follows, or tries to follow, those fields, turning the attached wheel. In a brushed motor, energy is transferred by brushes contacting the rotating shaft of the motor. Energy is transferred in a brushless motor electronically, eliminating physical contact between stationary and moving parts. Although brushless motor technology is more expensive, most are more efficient and longer-lasting than brushed motor systems.

Hub motor are typically brushless motors (sometimes called brushless direct current motors or BLDC), which replace the commutator and brushes with half-a-dozen or more separate coils and an electronic circuit. The circuit switches the power on and off in the coils in turn creating forces in each one that make the motor spin. Since the brushes press against the axle of a normal motor, they introduce friction, slow it down, make a certain amount of noise, and waste energy. That's why brushless motors are often more efficient, especially at low speeds

The outer-rotation hub motor systems are type of motors that have capacity of producing high torque at the low speed space. Because the machine torque changed directly proportional according to the machine's diameter's square, need of high moment can be overcome by using high diameter. Permanent- magnet synchronous hub motor that we used at the system has $48 \mathrm{~V}$ and the motors can produce $1 \mathrm{~kW}$ of power.

\section{TRACTION CONTROL OF ELECTRICAL VEHICLES}

The most important and disadvantageous side of mechanic differential gear which take part at the cars using daily life is surely that when one of the wheels cannot hold the road and a result skidding and cannot transfer power to the other wheel. At the two motor vehicles, subject of this study, one of the wheel can produce power independently from the other one. So, one of the wheels has been on the ice or snow surface, doesn't obstruct the vehicle's moving. At the motors which are used, torque control can be done by current control [7].

Antislip control and slip ratio control in an electric vehicle have the benefit of improving the driving stability of a vehicle on a low road. However, problems arise in coordination with the accelerator, including difficulty in switching between traction control and torque control with the accelerator without creating abrupt changes in the driving force, and the inability to obtain an arbitrary driving torque even though a large driving force can be obtained by slip ratio control $[8,9]$.
Maximum value of torque applied on the wheels at the low friction surfaces is not related to the power of motor but related to holding of the wheel to the surface. The main two factors are total vehicle weight of each wheel and friction coefficient of between the surface and the wheel $[10,11,12,13]$.

In order to create a force of wheel at the surface of the road and the moving direction, it should a bit slip. According to this, a wheel transferor and drive effort, it turns more than the needs of the road that go through. Similarly, it will turn less than the needs of the road that go through. Friction torque is connected to the condition of the wheel and the road as well as the load amount and drive force. In order to move of the vehicle, the power produced by motor should overcome the amount of road load. In a vehicle, Slip ratio is the proportion of the difference between the velocity of wheel and the actual velocity of vehicle to the velocity of wheel $[14,15]$.

The wheel slip ratio, which is defined as

$$
\begin{array}{ll}
s=\frac{\omega \cdot r-V_{X}}{\omega \cdot r}, & \text { for driving } \\
s=\frac{V_{X}-\omega \cdot r}{V_{X}}, & \text { for braking }
\end{array}
$$

where $r$ is the wheel radius, $\omega$ is the wheel angular velocity, $V_{X}$ is the actual velocity of vehicle.

As shown in Figure 1, a tire-road longitudinal friction coefficient $\mu$ is defined through the ratio between the traction force and the normal force.

$$
\mu=\frac{F_{x}}{F_{n}}
$$

$\mathrm{F}_{\mathrm{x}}=\mu \mathrm{F}_{\mathrm{n}}$

where $F_{x}$ is the traction force and $F_{n}$ is the the normal force as shown in figure 1 , wheel model of a vehicle has been shown. This friction coefficient depends on various factors, including the type of tire, the tire air pressure, the road condition, the normal forces [16]. In several works, the friction coefficient is modeled through semi-empirical formulas, which reproduce the steady-state wheel behavior. Usually, vehicles travel through variable road conditions; therefore, the results of empirical formulas may not represent the physical model with sufficient fidelity [16,17].

In traction control, it is necessary to consider the dynamic behavior of the friction coefficient to control the traction forces with a dynamic response that is fast enough to avoid the loss of traction (skidding). Wheel model of a vehicle is shown in Figure 2.

\begin{tabular}{llllll}
\hline Copyright (C) BAJECE & ISSN: 2147-284X & Special Issue 2015 & Vol.3 & No.4 & http://www.bajece.com
\end{tabular}




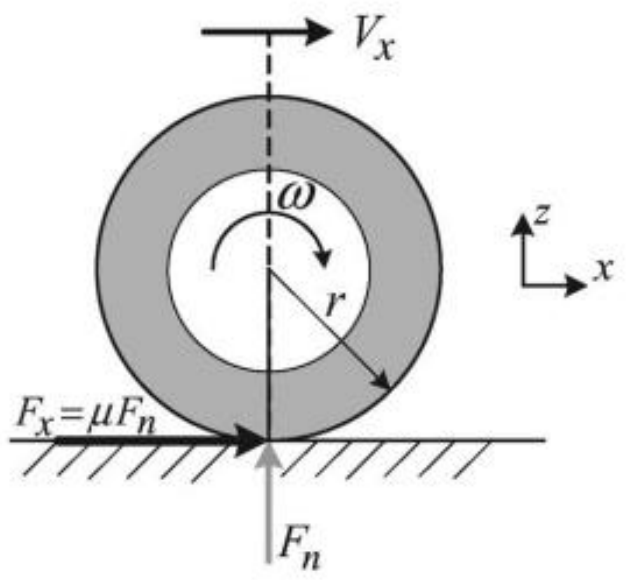

Fig.1. One wheel model of a vehicle

This friction coefficient depends on various factors, including the type of tire, the tire air pressure, the road condition, the normal forces.

In order to calculate the force of the wheel transferred at the road, a tire model has been used. At the input of this model, normal force of the tire, torque of the axle shaft and vehicle speed have been found, at the output, angular speed of the tire, torque and force applied on the road can be found. In order to calculate the force of the tires applied on the road, tires model is being used. Mostly used type models Magic Formula [18], Burckhardt models are used at modelling of tires. In this paper the Burckhardt model $[5,19]$ will be used, as it is particularly suitable for analytical purpose while retaining a good degree of accuracy in the description of the friction coefficient.

Based on Burckhardt model, the velocity dependent braking effort coefficient between the tire and the road has the following form

$\mu(s, v)=\left[C_{1}\left(1-e^{-C_{2} s}\right)-C_{3} s\right] e^{-C_{4} s v}$

Where $\mathrm{C}_{1}$ is the maximum value of friction curve; $\mathrm{C}_{2}$ is the friction curve shape; $\mathrm{C}_{3}$ is the friction curve difference between the maximum value and the value at $\lambda=1$; and $\mathrm{C}_{4}$ is wetness characteristic value. By changing the values of parameters $\mathrm{C}_{1-}$ $\mathrm{C}_{4}$, many different tire-road friction conditions can be modeled. The parameters for different road surfaces are listed in Table 1

TABLE I

TIRE-ROAD FRICTION PARAMETERS

\begin{tabular}{|c|c|c|c|c|}
\hline Surface Conditions & $\mathbf{C}_{\boldsymbol{1}}$ & $\mathbf{C}_{\mathbf{2}}$ & $\mathbf{C}_{\boldsymbol{3}}$ & $\mathbf{C}_{\boldsymbol{4}}$ \\
\hline Dry asphalt & 1.029 & 17.16 & 0.523 & 0.03 \\
\hline Dry concrete & 1.197 & 25.168 & 0.5373 & 0.03 \\
\hline Snow & 0.1946 & 94.129 & 0.0646 & 0.03 \\
\hline Ice & 0.05 & 306.39 & 0 & 0.03 \\
\hline
\end{tabular}

\section{EXPERIMENTAL SETUP DESIGN AND RESULTS}

In the systems, as the main metal is low carbonic structure steel at the quality of St 37.2, strap and two hub motors have been used. An experiment mechanism has been completed in order to transfer simulation works done at the computer environment to the practice. Longitudinal force of the tire applied on the road has been accepted as load. There are two hub motors at the experiment mechanism. Secondary hub motor will be used for load. Driving system of hub motor has been formed by inverter, digital signal processing and position sensor. According to the information of rotor position knowledge of location position, digital signal processing determines the phase for giving energy and switching are done. For stable torque production, these processes should be completed at the same time with the rotor position. Because real systems are moving systems and it is difficult and expensive to complete measurements at the electrical vehicles, experiment mechanism has been created for modelling electrical vehicles. Experimental setup is illustrated in Figure 2.

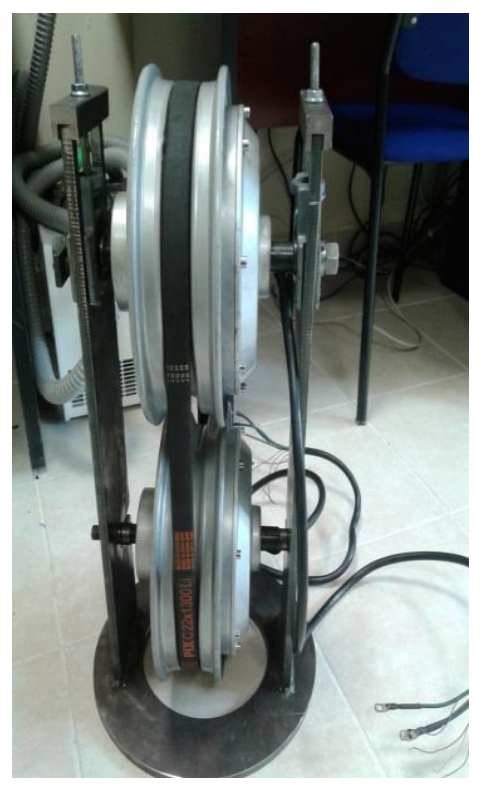

Fig 2. Experimental Setup

In this study, graphics of the friction coefficient and slip ratio as depend on vehicle speed is shown following. When speed increases friction coefficient connected with slip ratio decreases. This simulation was conducted on four road surface states dry asphalt (green), dry concrete (blue), snow (red), ice (turquois). In Figure 3, the shapes of slip ratio-friction coefficient for four different road conditions with a vehicle speed of $10 \mathrm{~m} / \mathrm{s}$ are illustrated. 


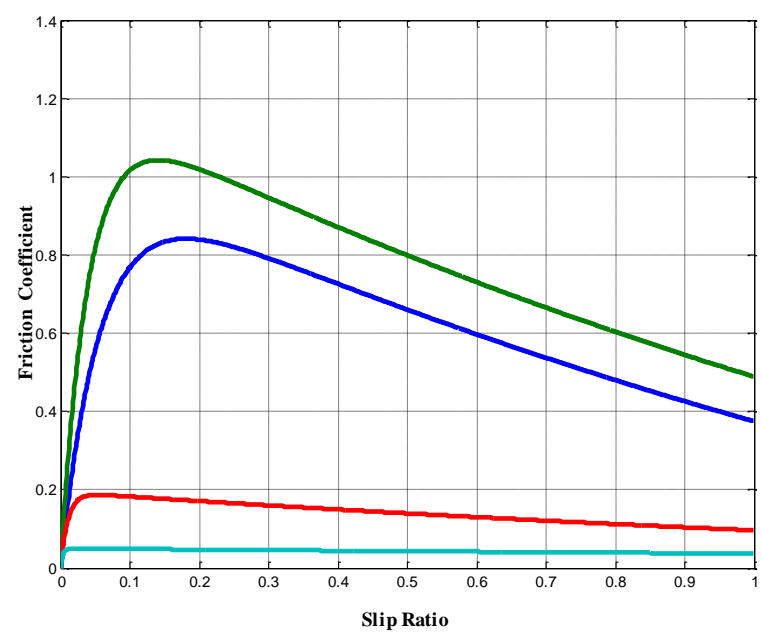

Fig 3. Slip ratio -friction coefficient graphics for different road conditions with a vehicle speed of $10 \mathrm{~m} / \mathrm{s}$

In Figure 4, the shapes of slip ratio-friction coefficient for four different road conditions with a vehicle velocity of $30 \mathrm{~m} / \mathrm{s}$ are illustrated.

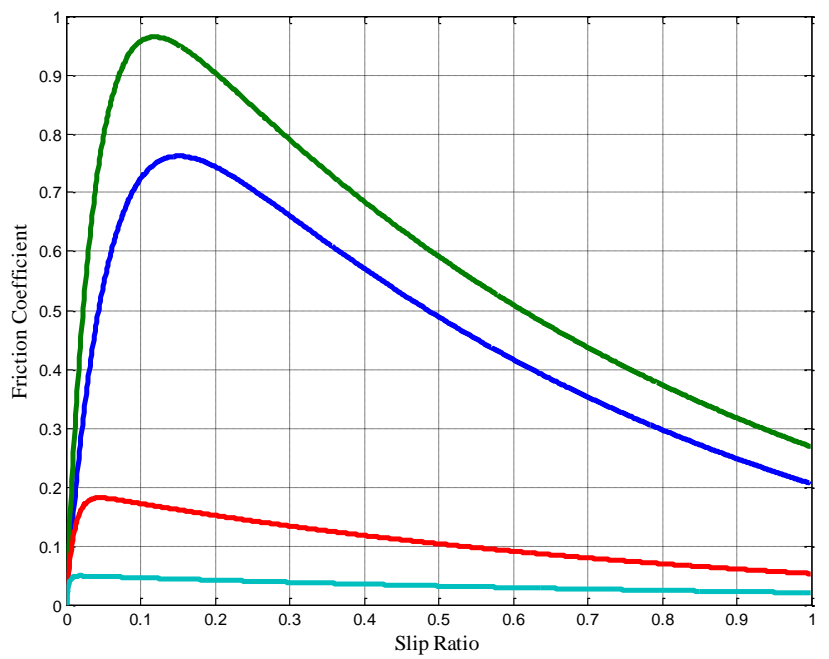

Fig 4. Slip ratio-friction coefficient graphics for different road conditions with a vehicle velocity of $30 \mathrm{~m} / \mathrm{s}$

At the Figure 3 and Figure 4, Slip ratio-friction coefficients for different road conditions, at the speed of $10 \mathrm{~m} / \mathrm{s}$ and $30 \mathrm{~m} / \mathrm{s}$, by using Burckhardt model have been displayed. As speed and slip ratio increases, friction coefficient decreases. When a tire is locked, the braking effort coefficient falls to its sliding value. As a result, the vehicle will lose directional control and stability.

Slip ratio has been given as the shape of trapeze and change of wheel speed has been illustrated in Figure 5.

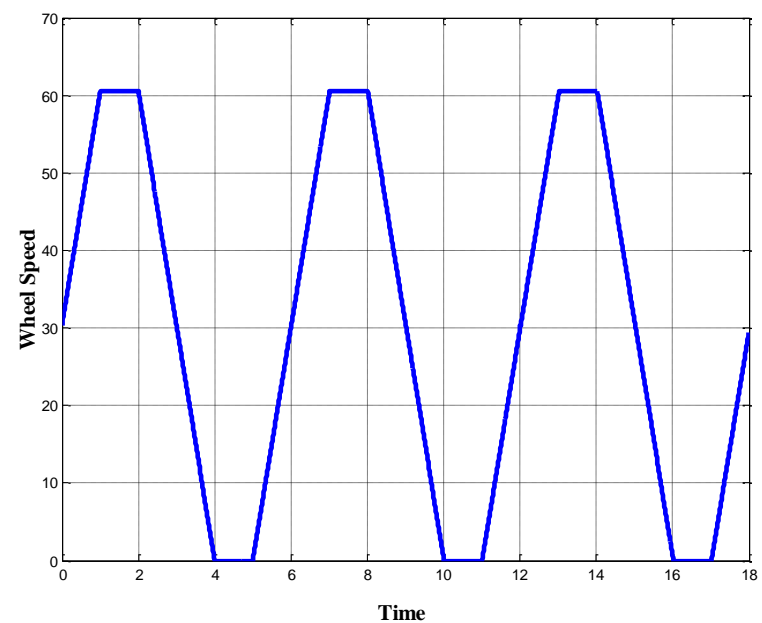

Fig 5 Angular speed of the wheel graphics when slip in the shape of trapeze with vehicle speed of $10 \mathrm{~m} / \mathrm{s}$

Slip ratio has been given as the shape of trapeze and change of wheel speed has been illustrated in Figure 6 .

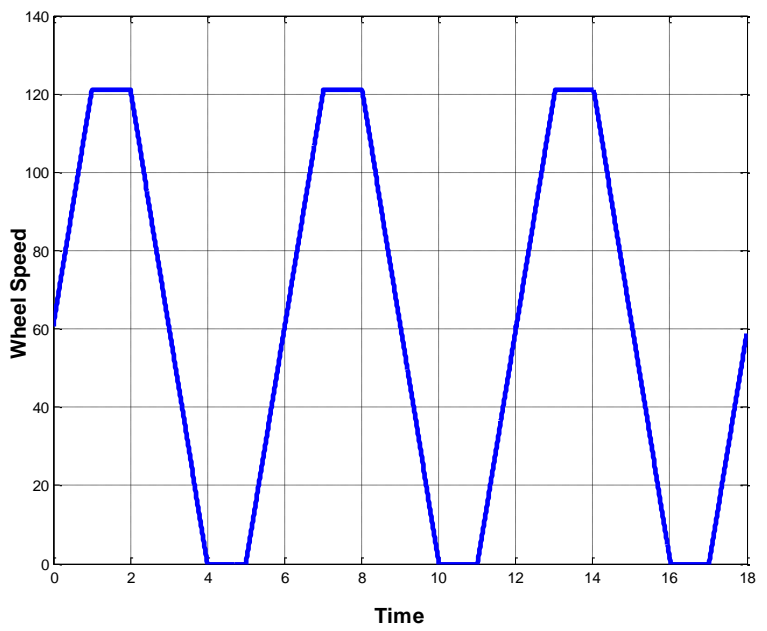

Fig 6. Angular speed of the wheel graphics when slip in the shape of trapeze with vehicle speed of $20 \mathrm{~m} / \mathrm{s}$

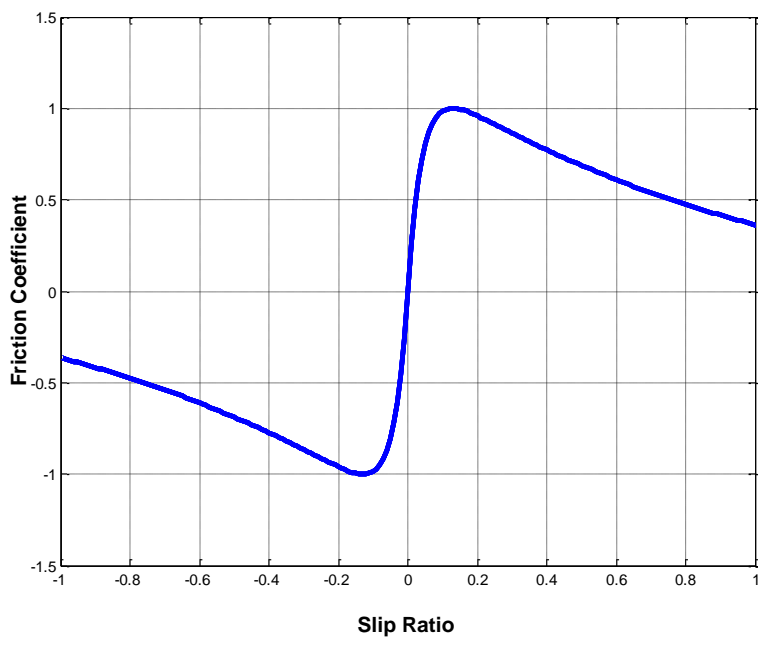

Fig 7. Friction coefficient- Slip Ratio Curve of vehicle speed $10 \mathrm{~m} / \mathrm{s}$ 
The model between the friction coefficient $\mu$ and slip ratio at the vehicle speed of $10 \mathrm{~m} / \mathrm{s}$ is shown in Figure 7 .

At figure 8 and figure 9, Slip has been given in the shape of trapeze and connected to the vehicle speed, wheel speed curves have been shown. Wheel speed was estimated using the slip chances between -1 to 1 .

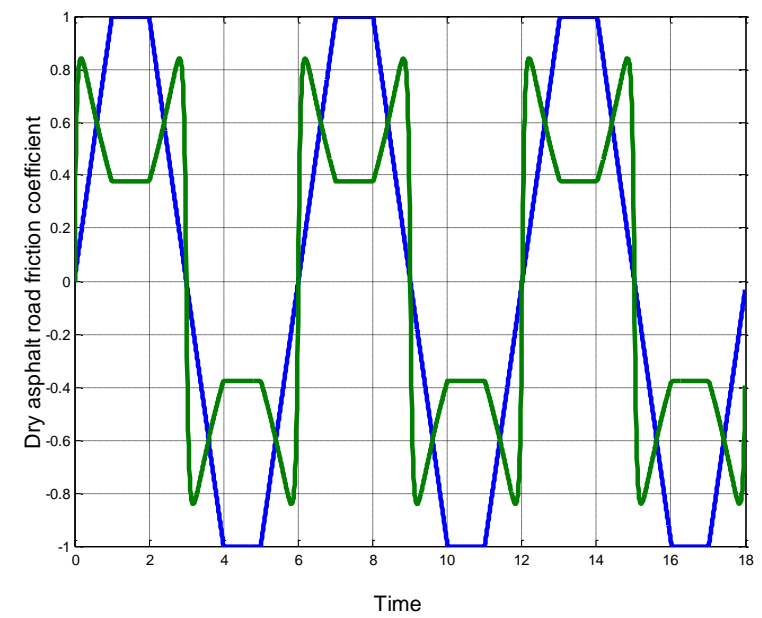

Fig 8. Dry asphalt road's coefficient of friction graphics when slip in the shape of trapeze at vehicle velocity of $10 \mathrm{~m} / \mathrm{s}$

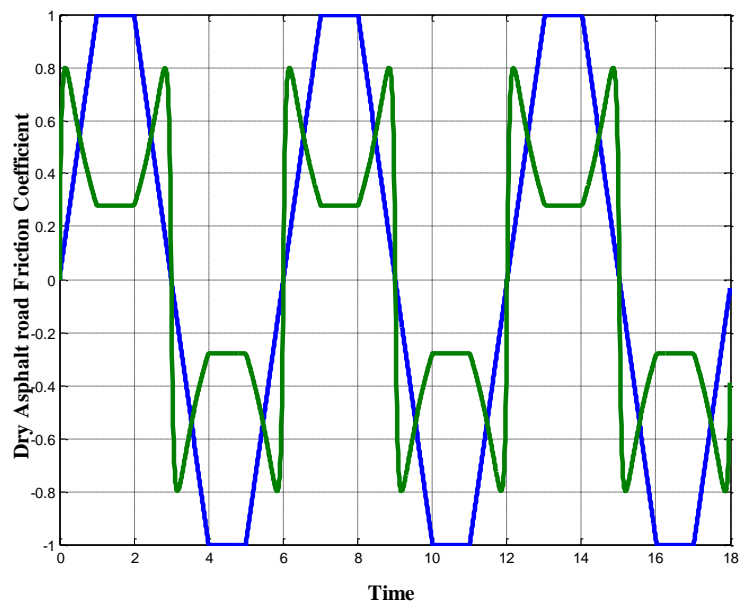

Fig 9. Dry asphalt road's coefficient of friction graphics when slip in the shape of trapeze at vehicle velocity of $20 \mathrm{~m} / \mathrm{s}$

At figure 8 and figure 9, when slip changes between -1 and 1 , in the shape of trapeze, at the dry asphalt road, speed of $10 \mathrm{~m} / \mathrm{s}$ and $20 \mathrm{~m} / \mathrm{s}$, friction coefficients have been shown. This effects longitudinal force of wheel and as a result it effects load force.

At the figure 10, when slip ratio changes in the shape of trapeze under different road conditions (dry asphalt, dry concrete, snow and ice).

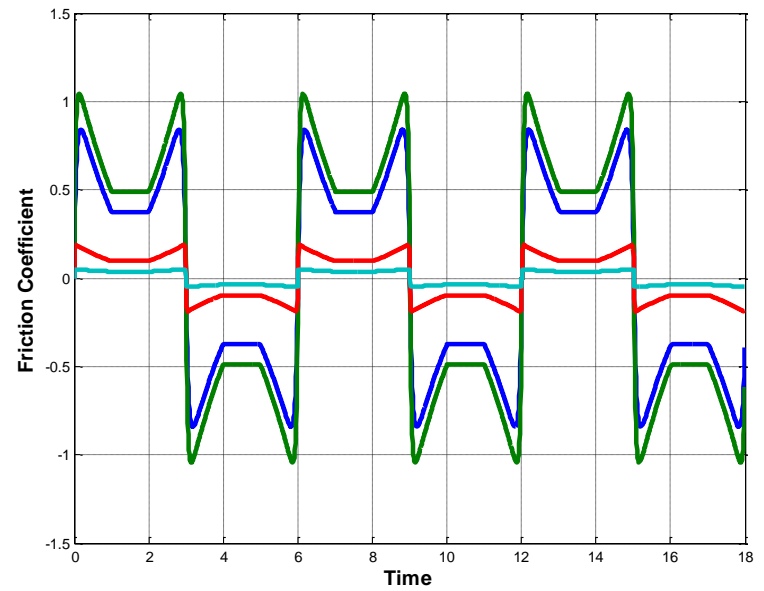

Fig 10. Friction coefficient graphics for different road conditions of vehicle velocity of $10 \mathrm{~m} / \mathrm{s}$

Simulation study of friction coefficients has been shown. The highest and the best result friction coefficient is dry asphalt and the lowest one is icy road.

\section{CONCLUSIONS AND DISCUSSION}

Because the real systems are moving systems and it is difficult and expensive to complete measurements, an experiment mechanism has been created. Speed of hub motor used at the electrical vehicles, connected to slip has been calculated using simulation study with $C$ language.

There are also different vehicle traction systems; it is thought that directly tire drive systems will be used widespread in the future. By controlling each tire hub motors independently, breakdown of any motor can be prevented, so reliability of the vehicle's drive systems increases.

Because of increasing amount of pollution and decreasing amount of oil reserves, study of electrical vehicles should be speed up. In order to produce cheaper driving systems of electrical vehicles, control systems, projects should be started about equipment's of electrical vehicles. By modelling the precious studies, more productive, lighter, more intelligent and cheaper components should be produced. Technical staff should be raised about power electronics and design of electronics circuit. It is not impossible to produce this technology be encouragement of the state, progress of the industrials and common projects groups of the universities.

\section{ACKNOWLEDGMENTS}

This paper was supported by Abant İzzet Baysal University Engineering Faculty Research and Development Laboratory and Duzce University Scientific Resarch Project Coordination.

The study is selected from National Engineering Research Symposium 2015 (Ulusal Mühendislik Araştırmaları Sempozyumu) UMAS 2015 (Duzce University). 


\section{REFERENCES}

[1] Emadi, M. Ehsani, and J. M. Miller, Vehicular Electric Power Systems: Land, Sea, Air, and Space Vehicles, New York: Marcel Dekker, December, 2000.

[2] A. Emadi, S.S. Williamson, A. Khaligh, "Power electronics intensive solutions for advanced electric, hybrid electric, and fuelcell vehicular power systems", IEEE Transaction on PowerElectronics, Vol. 21, Issue 3, May Page(s):567- 5772006.

[3] Koca, Özmen, G., and Akpolat. Z. H., "Bulanık Mantık ve Erişim Kuralı Yaklaşımını Kullanarak Bir Elektrikli Aracın Dayanıklı Hız Denetimi." Gazi Üniversitesi Politeknik Dergisi, 9(2): 93-103, 2006.

[4] Kerem, A., "Elektrikli Araç Teknolojisinin Gelişimi ve Gelecek Beklentileri." Mehmet Akif Ersoy Üniversitesi Fen Bilimleri Enstitüsü Dergisi ,5 (1): 1-13, 2014.

[5] Burckhardt, M., Fahrwerktechnik: Radschlupf - Regelsystmeme Würzburg: Vegel Verlog, 1993.

[6] Bulgu A.E., “ Tekerlek motorlu seri hibrit elektrikli araçlar için kontrol algoritmalarının geliştirilmesi” Yüksek Lisans Tezi, İTÜ Fen Bilimleri Enstitüsü, İstanbul, Türkiye, 2010.

[7] D.Azmi.,"Elektrikli Otomobiller ve Patinaj Engellenmiş bir doğrudan sürüşlü elektrikli otomobil tahrik sistemi." İstanbul Üniversitesi Mühendislik Fakültesi Journal of Elektrical \& Electronics, Volume 2, Number 1-383-393, 2002.

[8] M. Yoshımura, H.Fujımoto, "Driving Torque Control Method for Electric Vehicle with In-Wheel Motors", Electrical Engineering in Japan, Vol. 181, No. 3, 2012.

[9] D.O.S.Yin, Y.Hori "A novel traction control for EV based on maximum transmissible torque estimation", IEEE Trans Industrial Electronics n;56(6), 2009.

[10] Z. Rahman., K.L.Butler, M.Ehsani "Effect of Extended-Speed, Constant- Power Operation of Electric Drives on the Design and Performance of EV-HEV Propulsion System", SAE,2000-011557, (2000).

[11] Rahman Z., Ehsani M., Butler K.L., (2000) “An Investigation of Electric Motor Drive Characteristics for EV and HEV Propulsion Systems" SAE 2000-01-3062.

[12] Husain I., Islam M.S., (1999) "Design, Modeling and Simulation of an Electric Vehicle System", SAE 1999-01-1149.

[13] Çınar M.A., Gündoğan Ç., Erfan Kuyumcu F., "Elektrik Tahrikli Taşıtlar için Çekiş Kontrol Sistemi Simülasyonu”, ELECO’2004 Elektrik-Elektronik-Bilgisayar Mühendisliği Kongresi, 296300,2004

[14] T. Gillespie, Fundamentals of Vehicle Dynamics. SAE - Society of Automotive Engineers, 1992.

[15] Sakai, S.; Sado, H.; Hori, Y. Anti-skid control with motor in electric vehicle. In Proceedings of the 6th International Workshop on Advanced Motion Control, Nagoya, Japan, 30 March-1 April pp. 317-322,2000.

[16] G. A. Magallan, C. H. De Angelo, and G. O. Garcia, "Maximization of the traction forces in a $2 \mathrm{WD}$ electric vehicle," IEEE Transactions on Vehicular Technology, vol. 60, no. 2, pp. 369-380, 2011

[17] C. Canudas-de Wit, P. Tsiotras, E. Velenis, M. Basset, and G. Gissinger, "Dynamic friction models for road/tire longitudinal interaction,"Veh. Syst. Dyn., vol. 39, no. 3, pp. 189-226, Mar. 2003.

[18] Pacejka, H.B.; Bakker, E. The magic formula tyre model. Vehicle. Syst. Dyn. Int. J. Veh. Mech. Mobil. 1993, 21, 1-18.

[19] Oudghiri, M.; Chadli, M.; Hajjaji, A.E. Robust fuzzy sliding mode control for antilock braking system. Int. J. Sci. Tech. Autm. Control, $1,13-28,2007$.

\section{BIOGRAPHIES}

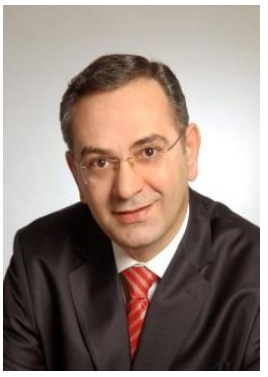

Cetin ELMAS was born in Bursa in Turkey. He received the B.S. degree in electrical and electronics education and the M.Sc. degree in electrical education from Gazi University, Ankara, Turkey, in 1986 and 1989, respectively, and the Ph.D. degree in electronic and electrical engineering from the University of Birmingham, U.K., in1993. From 1987 to 1989 , he was a research assistant with Gazi University, Faculty of Technical Education Assistant with Gazi University, From 1994 to 1995, he was an assistant professor. He is currently a full professor and the head of the department of electrical machinery. His research interests include power electronics, electrical machines and drivers intelligent control, digital signal processing, and engineering technology education.

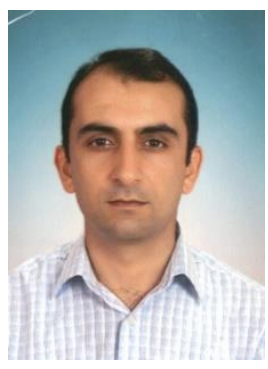

Ugur GUVENC was born in Zile in Turkey. He received the B.Sc. degree in electrical education from Abant İzzet Baysal University, Bolu, Turkey in 2002, M.Sc. degree from Gazi University, Turkey in 2005 and the Ph.D. degree from Gazi University, Turkey in 2008. He is currently an Assistance Professor in the Department of Electrical Education, Faculty of Technical Education, Düzce University, Turkey. His main interests are in artificial intelligent, power system and image processing.

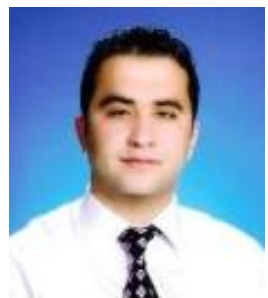

Muhsin Uğur DOĞAN was born in Bolu, Turkey . $\mathrm{He}$ received his B.Sc. degree in Electronic Engineering from the Erciyes University in Kayseri, in 2002. He received his Master Degree in ElectricalElectronical engineering from the Zonguldak Karaeelmas University. He works at Abant Izzet Baysal University, Vocational High School, Department of Electronics and Automation. His main electrical machines and driver. interests are in control systems, electric vehicle, 